\title{
Duration Prediction Models for Construction Projects in Middle East
}

\author{
Karim M. M. El-Dash \\ Civil Engineering Department, \\ Faculty of Engineering, \\ Benha University, Shoubra, Egypt \\ k_eldash@hotmail.com
}

\author{
Osman M. O. Ramadan \\ Faculty of Engineering, Cairo \\ University, Higher Technological \\ Institute, $10^{\text {th }}$ of Ramadan City, Egypt \\ omoramadan@yahoo.ca
}

\author{
Waleed Mahfouz M. A. Youssef \\ Structural Engineering Department, \\ Faculty of Engineering, \\ Cairo University, Giza, Egypt \\ cvlmaster@yahoo.com
}

\begin{abstract}
Construction industry is one of the most influential motivators of a national economy. The success of construction projects is indispensable to sustain a robust economy. Completion time is important for construction projects, nevertheless project multifaceted objectives, sophisticated nature, inherent uncertainties, and risks are success impediments and can cause time overrun. Stochastic models and simulation scheduling techniques are developed to predict the risk and uncertainty effects on construction projects' duration. The objective of this research is to develop models that predict the activity durations based on actual data from similar projects. The study introduces comprehensive statistical regression models using historical data of about 84,000 activities in Egypt, Kuwait, and Saudi Arabia. The activities encompass engineering, procurement and construction (EPC) activities for most disciplines of construction projects. The regression models can be utilized to predict more reliably the activities' duration.
\end{abstract}

Keywords-construction projects; duration prediction; regression models; Middle East

\section{INTRODUCTION}

\section{A. Construction Industry}

Construction is a fundamental activity and one of the most predominant motivating forces for any national economy. It plays a prime role in economic development, and it is influencing and influenced by the gross domestic product (GDP) of any country [1, 2]. Construction projects are dissimilar in size, type, location, site conditions, inputs and outputs, something that makes each project unique and consequently the standardization of construction processes becomes extensively difficult and risky.

\section{B. Construction Projects Performance}

Intrinsic risks and increasing complexity of modern construction projects cause delays and cost overruns to become common facts in the construction industry. From the projects completed worldwide between 1974 and 1988, 90\% were delivered late with a cost overrun varying between 50\% and $80 \%$ [3]. Moreover, delays ranged from one up to 252 months in some cases [4].

\section{Construction Delays}

Delays may lead to disruption of work, loss of productivity, late project completion, increased additional time-related costs, non-completion, termination of contract, etc. [5]. Therefore, studying construction delays and potential risks becomes an exigent prerequisite in order to control the estimated time for a project's duration. Overall project's duration enables contractors to prepare their strategy and methodology. Authors in [6-9] studied diverse types of projects, e.g. large buildings and public utilities in Kingdom of Saudi Arabia (KSA) [6-9], grouping the causes of delays in 6 groups: contractor performance, owner and consultant administration, early planning and design, government regulation and policies, site and environmental conditions and supervision and field inspection. The study in [7] allocated the delay responsibility first to contractors, which were responsible for about the $44 \%$ of delays. In Kuwait, authors in [10,11] identified the key causes of delays in private residential projects. Author in [12] incorporated 42 risk factors affecting time overrun in UAE founding that the most significant factors are inflation and sudden changes in prices. Author in [13] studied the performance of construction projects in Jordan and found that amongst 130 projects 106 were delayed (81.5\%). He indicated the major three causes of delay as: poor design (24.6\%), change in orders (15.4\%), and weather (12.3\%).

\section{Estimation Models for Project Duration}

The project's realistic duration is important because it always serves as a crucial benchmark for assessing performance efficiency of a project's time and cost [8]. The project's estimated duration is often based on an owner's feasibility study irrelevant to the construction plan, the activities' sequential strategy, or the available resources. Consequently, the project's estimated duration is often not reliable and therefore represents a significant threat during construction. Therefore, the estimation of realistic project duration can be considered the prime parameter towards reducing the probability of delay. Also, it consequently decreases the expected disputes between owners and contractors. The prediction of a project's overall duration constitutes a continual concern for construction researchers and project managers. The techniques used for estimating project's overall fair duration have been outlined in many researches and the considered input parameters include the degree of complexity, the scope of work, the area of the project, the 
number of levels, the function of building, the client type, the procurement route, the market constraints or opportunities, and the starting date of the project [14-22]. A model was developed to predict project duration based on project time-budget relationship in 1974 through investigation of 370 building projects in Australia [16]. Another model using historical data to develop different quantitative regression models to estimate the project's duration and price was developed in [13]. The sample consists of 130 public projects in Jordan between 1990 and 1997. Authors in [18] developed a third model through surveying the performance of 2554 distinct building projects in the UK between 1998 and 2004. They produced a linear regression model for project duration according to building function classification. Authors in [23] developed another model, as they investigated real data for a sample of 140 construction projects in Jordan between 1994 and 2002. Authors in [24] developed a model by focusing the study on 113 public projects in Jordan between 1994 and 2002. They derived multiple regression models that predict the project cost and duration depending on scope, area, estimated budget, and estimated duration of the project.

\section{E. Estimation of Activity Duration}

Another parameter in reducing the probability of construction delay is estimating activity duration properly. The duration estimate depends on numerous factors including, construction execution methodology, resource availability, work quantity, nature, work complexity, labor and equipment productivity, quality of field management, weather, site conditions, etc. [25]. It is believed that the more reliable are the activity calculated durations, the more accurate the project completion time will be. Authors in [26, 27] pointed that it is not essential for duration estimates to be consistently exact. All durations are only required to be reasonable, and subsequently, variations in activity durations will compensate each other, resulting in reasonably accurate project duration estimation. This estimation can be classified as deterministic and stochastic depending on project's nature, potential risks, productivity rates, available resources, site conditions, site location, project environment, levels of complexity, levels of quality, expert judgment, and degrees of uncertainty [28-31]. Nonmaterialized parameters such as uncertainty levels and potential risks were incorporated as a contingency percentage [31]. Stochastic estimations or simulation techniques were utilized to appraise and quantify the impact of uncertainty and potential risks on activity's duration in [30-34].

The prime objective of the current study is to provide a reliable technique for estimating activity durations for construction projects. This technique considers the actual behavior of similar activities and their potential risks affecting the performance of large construction projects. A variety of distinct regression models were generated to delineate the relationship between the estimated deterministic durations and their actual durations. The generated models provide a practical and easy tool for estimating the activity duration stochastically. This derivation expands previously reported studies and evaluates model predictions against the actual results from completed or currently running projects.

\section{METHODOLOGY AND SCOPE}

In order to predict more reliably activity durations, historic data from real projects were collected and analyzed. Estimated and actual durations, and budget values were compiled from existent construction projects in three countries: Egypt, Kuwait and KSA between 1998 and 2013. A set of descriptive statistical analyses and regression models were established in order to appraise the relationship between the estimated durations and budget against actual durations. Thirteen distinct projects were investigated covering a diverse sample of large construction projects for both public and private sectors including hospitals, high buildings, malls, hotels, stadiums, banks, administrative buildings, houses, infrastructure, and highway projects.

The study encompassed a large number of activities, approximately 84,000, inclusive of engineering, procurement and construction (EPC). Engineering activities represent all preparation activities such as shop drawings and materials submittals including samples, manufacturer data, mockups, and testing certificate activities. Procurement activities represent all activities needed to guaranty the delivery of the materials including contracts, letter of credits, manufacturing, shipping and delivery. Construction activities represent all tasks on site that require manpower and equipment to be carried out in order to produce a structure or a part of the structure. The analysis of activities categorized regression models based on the type of activities (EPC), the country, and CSI master format 1995 classification. During the study, various computer software packages such as Microsoft Access 2010, Primavera Project Planner 3.1, Primavera Enterprise 6.7, Table curve 2D 5.01, Sigma Plot 12.0 and SPSS 20.0 were utilized in order to collect, sort, analyze and derive statistical properties and regression models for actual and estimated durations.

\section{A. Data Description According to Type of Work}

The generated regression models were classified according to the type of activities as: (1) engineering-procurement activities (EPAs) and (2) construction activities (CAs). Descriptive statistical analysis of 66,500 CAs and 17,500 EPAs grouped by the estimated duration value is summarized in Table I. The results of the actual activity duration comparison with the estimated ones over 90 days aligned with the ones in [13] thus proving that they are close to each other. As illustrated in Table I, the smaller the estimated duration, the higher the duration slippage is. The ratio $\mathrm{Z}$ defines the relationship between the mean of actual durations and the estimated duration. Z-values are high for small estimated durations and small for high estimated durations. This unexpected ratio might be explained in $[26,27]$ as there is no time margin to compensate improperly estimated small durations. In the case of higher values of estimated durations, there is sufficient time to recover the delays internally on every activity level. Table I demonstrates that for estimated durations lesser than 4 days, the Z-values for EPAs are greater than those for CAs. Henceforth Z-values for EPAs become smaller than CAs for all values of estimated durations. 
TABLE I. STATISTICS OF ACTUAL DURATION VALUES FOR CONSTRUCTION ACTIVITIES AND ENGINEERING-PROCUREMENT ACTIVITIES

\begin{tabular}{|c|c|c|c|c|c|c|c|c|c|c|c|c|c|c|}
\hline & \multicolumn{7}{|c|}{ Construction activities } & \multicolumn{7}{|c|}{ Engineering-procurement activities } \\
\hline ED & $\begin{array}{l}\text { Activity } \\
\text { Number }\end{array}$ & $\begin{array}{c}\text { Mean } \\
\text { AD }\end{array}$ & Median & Mode & $\begin{array}{c}\text { Std Deviation } \\
\text { (days) }\end{array}$ & CV & $\mathbf{Z}$ & $\begin{array}{l}\text { Activity } \\
\text { Number }\end{array}$ & \begin{tabular}{|c|} 
Mean \\
AD
\end{tabular} & Median & Mode & $\begin{array}{c}\text { Std Deviation } \\
\text { (days) }\end{array}$ & $\mathbf{C V}$ & $\mathbf{Z}$ \\
\hline 1 & 1059 & 44 & 20 & 1 & 59.1 & 1.3 & 44.1 & 1927 & 86 & 55 & 7 & 105.6 & 1.2 & 85.6 \\
\hline 2 & 4413 & 82 & 28 & 1 & 110.3 & 1.3 & 41.1 & 39 & 88 & 70 & 1 & 99.7 & 1.1 & 44.2 \\
\hline 3 & 3987 & 62 & 8 & 2 & 107.2 & 1.7 & 20.7 & 56 & 35 & 6 & 6 & 92.9 & 2.6 & 11.7 \\
\hline 4 & 3638 & 73 & 17 & 3 & 108.2 & 1.5 & 18.1 & 19 & 94 & 27 & 3 & 152.5 & 1.6 & 23.6 \\
\hline 5 & 4086 & 83 & 17 & 5 & 158.0 & 1.9 & 16.6 & 75 & 75 & 39 & 4 & 85.9 & 1.1 & 15.0 \\
\hline 6 & 4591 & 98 & 41 & 6 & 122.2 & 1.2 & 16.3 & 128 & 22 & 6 & 6 & 43.0 & 2.0 & 3.7 \\
\hline 7 & 3340 & 93 & 31 & 7 & 140.0 & 1.5 & 13.3 & 285 & 36 & 10 & 6 & 65.1 & 1.8 & 5.2 \\
\hline 8 & 4033 & 70 & 24 & 8 & 100.6 & 1.4 & 8.7 & 96 & 44 & 30 & 30 & 45.5 & 1.0 & 5.4 \\
\hline 9 & 1120 & 80 & 25 & 9 & 114.2 & 1.4 & 8.9 & 4 & 66 & 15 & 4 & 109.2 & 1.7 & 7.3 \\
\hline 10 & 7858 & 71 & 22 & 10 & 109.0 & 1.5 & 7.1 & 374 & 42 & 19 & 12 & 57.7 & 1.4 & 4.2 \\
\hline 11 & 590 & 111 & 61 & 8 & 124.6 & 1.1 & 10.1 & 7 & 120 & 42 & 12 & 118.0 & 1.0 & 10.9 \\
\hline 12 & 5757 & 118 & 58 & 7 & 138.4 & 1.2 & 9.9 & 1277 & 58 & 20 & 12 & 79.3 & 1.4 & 4.8 \\
\hline 13 & 2602 & 36 & 18 & 10 & 75.7 & 2.1 & 2.8 & 43 & 46 & 43 & 7 & 43.7 & 0.9 & 3.6 \\
\hline 14 & 3809 & 109 & 60 & 14 & 125.5 & 1.1 & 7.8 & 5516 & 65 & 25 & 13 & 90.9 & 1.4 & 4.6 \\
\hline 15 & 2934 & 135 & 79 & 14 & 159.5 & 1.2 & 9.0 & 599 & 54 & 23 & 16 & 67.2 & 1.3 & 3.6 \\
\hline 20 & 829 & 141 & 105 & 19 & 137.2 & 1.0 & 7.0 & 159 & 91 & 48 & 22 & 100.4 & 1.1 & 4.5 \\
\hline 25 & 615 & 111 & 61 & 4 & 138.7 & 1.2 & 4.4 & 258 & 77 & 29 & 28 & 116.9 & 1.5 & 3.1 \\
\hline 30 & 604 & 161 & 116 & 34 & 160.8 & 1.0 & 5.4 & 917 & 92 & 45 & 29 & 95.2 & 1.0 & 3.1 \\
\hline 40 & 165 & 127 & 90 & 46 & 128.8 & 1.0 & 3.2 & 108 & 84 & 49 & 11 & 90.9 & 1.1 & 2.1 \\
\hline $\mathbf{5 0}$ & 1778 & 76 & 53 & 4 & 90.0 & 1.2 & 1.5 & 54 & 145 & 105 & 9 & 148.5 & 1.0 & 2.9 \\
\hline 60 & 144 & 130 & 97 & 61 & 108.6 & 0.8 & 2.2 & 547 & 126 & 98 & 47 & 113.6 & 0.9 & 2.1 \\
\hline 90 & 119 & 152 & 115 & 19 & 123.9 & 0.8 & 1.7 & 347 & 149 & 120 & 36 & 116.6 & 0.8 & 1.7 \\
\hline 120 & 10 & 380 & 355 & 50 & 318.4 & 0.8 & 3.2 & 324 & 188 & 170 & 47 & 123.9 & 0.7 & 1.6 \\
\hline 150 & 4 & 274 & 151 & 5 & 351.7 & 1.3 & 1.8 & 144 & 218 & 197 & 196 & 141.7 & 0.6 & 1.5 \\
\hline 180 & & & & & & & & 87 & 208 & 186 & 33 & 153.5 & 0.7 & 1.2 \\
\hline
\end{tabular}

$\mathrm{ED}=$ estimated duration (days), $\mathrm{AD}=$ actual duration (days), $\mathrm{CV}=\mathrm{Std} / \mathrm{AD}, \mathrm{Z}=\mathrm{Mean} \mathrm{AD} / \mathrm{ED}$

The deduced coefficient of variation (CV) for actual duration values from Table I shows that the $\mathrm{CV}$ for $\mathrm{CAs}$ ranges from 0.72 to 2.1 , whereas the $\mathrm{CV}$ for engineering-procurement ranges between 0.65 and 2.65. Furthermore, the values of $\mathrm{CV}$ for EPAs are not always higher than the ones for CAs for similar values of estimated duration. Planners and project managers can utilize the data included in Table I and the probability density functions published in $[35,36]$ to forecast a project's overall duration. Overall project duration could be more than the one normally expected due to the difference of calculated activities duration with the use of conventional estimation techniques over the deduced values. However, the deduced values allow the opportunity for early planning through innovative methodologies and alternative plans to avert any probable delays.

\section{B. Regression Models for Construction Activities}

Regression models for CAs were generated for the 3 countries under study to provide a regional model of Middle East. The investigation encompassed 66,500 distinct CAs to develop a regression model describing the relationship between activities' estimated duration and their pertinent average actual durations as described by (1)-(2):

$$
\begin{aligned}
& y=a+b \ln (x) \\
& y=a+b x
\end{aligned}
$$

where $y$ is the average value of actual duration, $x$ is the estimated duration value and $a, b$ are constants. Figure 1 illustrates the exponential growth in the average actual duration against estimated duration until the estimated duration reaches approximately 30 days, afterwards the increasing rate remains, however, with a moderate slope. Another analysis of the construction activities was conducted for each individual country in order to estimate the impact of potential risks and the particular uncertainty level specific to each country. The regression models extracted for construction activities in Kuwait, Egypt and KSA are shown in Figure 1.

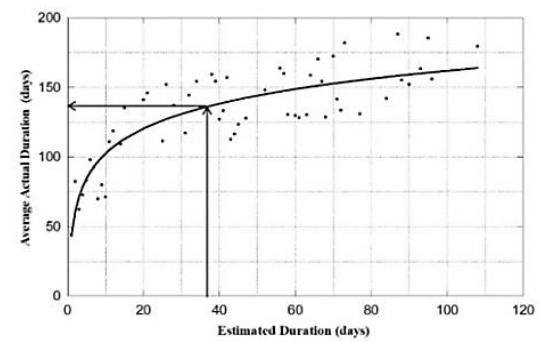

Fig. 1. Regression model for actual durations versus estimated durations for construction activities in the three countries

Kuwait and Egypt are represented by (1) while the case of KSA is mathematically represented by (2). These regression models can be utilized to predict the average anticipated duration for any activity based on its relevant estimated duration calculated based on activity's scope and productivity rate. Figures 2(a)-(c) show the relationships between the average actual duration and the estimated duration for construction activities in Egypt, Kuwait and KSA, respectively. As demonstrated in Figure 2(a) the trend of average actual duration increases rapidly until the estimated duration of 
approximately 10 days. Afterwards, the slope slowly decreases until estimated duration of 20 days. Finally, the curve almost becomes horizontal. Meanwhile, the average actual durations in Kuwait are rapidly increasing until estimated durations reach 20 days, and then the slope becomes moderate as illustrated in Figure 2(b). It is worth noting that the relation between the average actual and estimated durations in KSA is linear with consistent growth from the beginning till the end as shown in Figure 2(c). In general, the values of average actual durations pertinent to estimated durations less than 30 days are higher in all cases. The highest values for this range were recorded in Kuwait due to the fluctuated levels of productivity rates, the strict application of quality control program, the lack of workforce in the local market, and the lack of planning and control by the subcontractors [10].

(a)

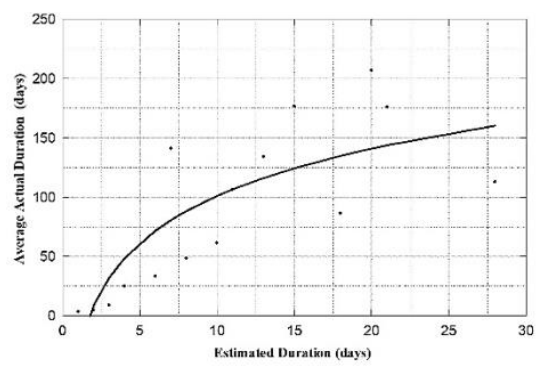

(b)

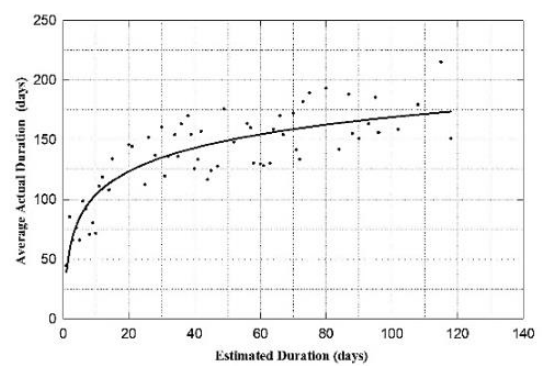

(c)

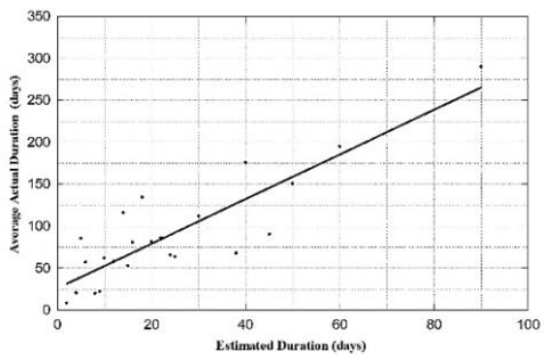

Fig. 2. Actual durations regression model for CAs versus estimated durations in: a) Egypt, b) Kuwait; and c) KSA

\section{Regression Models for Engineering-Procurement Activities}

The regression model for engineering-procurement activities was developed by analyzing 17,500 activities in the 3 countries. The best fit is a linear model as illustrated in Figure 3 and formulated by (2).

\section{Regression Models for Critical Activities}

The study of the actual performance of critical activities included approximately 12,900 critical activities constituting nearly the $15.4 \%$ in a sample of about 84,500 activities. Construction critical activities represent about $14 \%$ of total
CAs. The ratio of the critical EPAs is around $20 \%$ of the total EPAs. Comprehensive statistical study on critical activities proved that critical activities for all phases as well as for CAs are best described by (1), whereas, critical EPAs are best represented by (2). As evidently revealed in Figure 4, the ratio (Z-value) in CAs is higher than those for EPAs until the estimated duration of 40 days. Z-values are higher for EPAs than for CAs for estimated durations above 100 days due to delays in material delivery and poor coordination between main contractors and international suppliers [10, 36-38]. The values of $\mathrm{r}^{2}$ coefficient and equations' constants related to regression models of critical activities are exhibited in Table II.

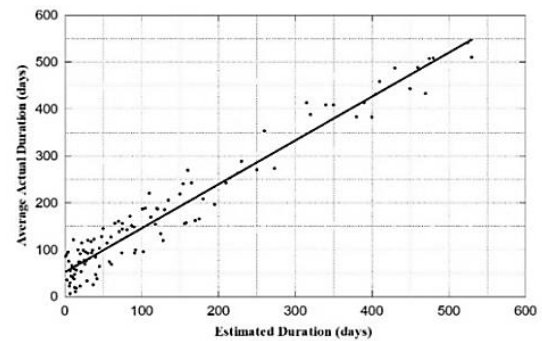

Fig. 3. Regression model for EPAs actual durations versus estimated durations in the three countries

(a)
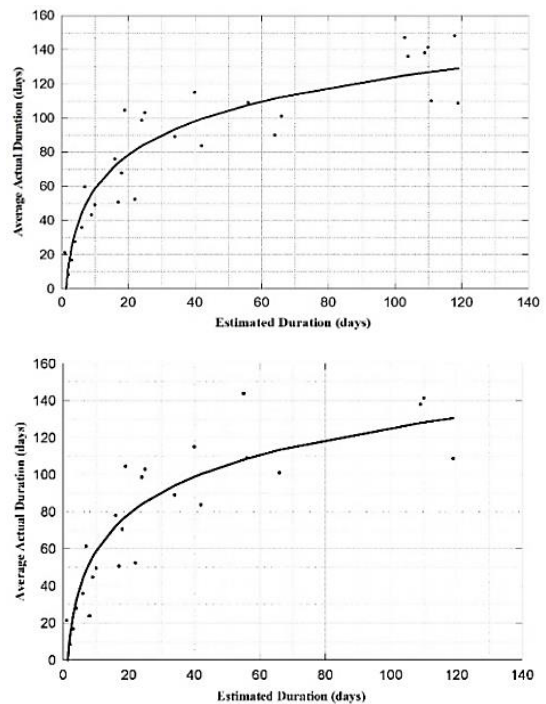

(b)

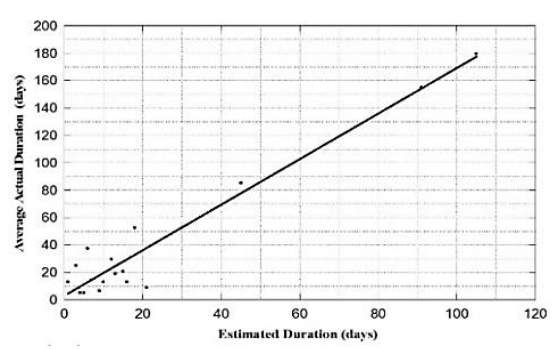

Fig. 4. Regression models for actual durations in the 3 countries grouped by phase of work: a) all phases, b) CAs, and c) EPAs

\section{E. Regression Models for Kuwait Grouped by CSI Divisions}

A thorough analysis was performed on the construction activities in Kuwait with results categorized according to CSI 
format. The analysis reveals that divisions: site works (02), masonry works (04), finishing works (09) and mechanical works (15) are best represented by (1). Division concrete works (03) is represented by (3), division doors and windows works (8) by (2), and division electrical works (16) by (4).

$$
\begin{aligned}
& y=a+b \sqrt{\mathrm{x}} \\
& y=a+b / \sqrt{x} \\
& y=a+b / x
\end{aligned}
$$

(a)

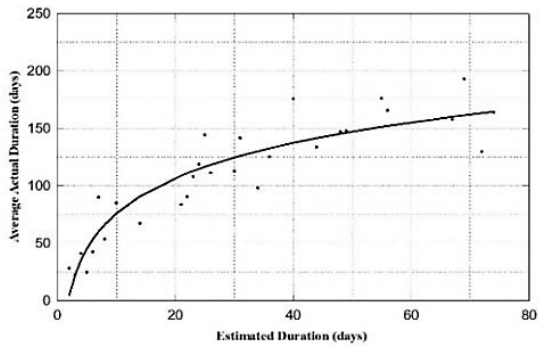

(b)

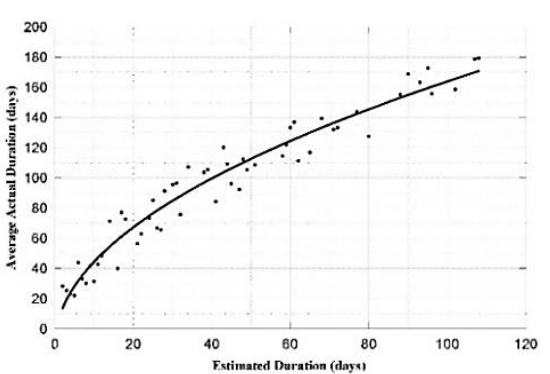

(c)

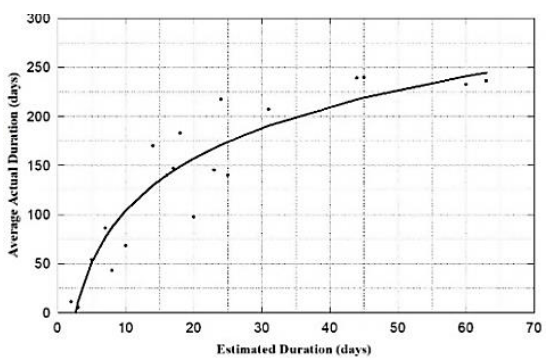

(d)

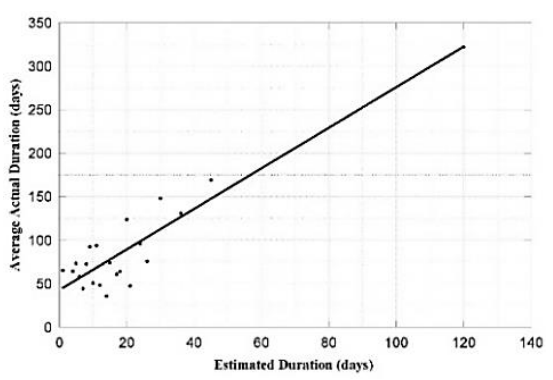

(e)

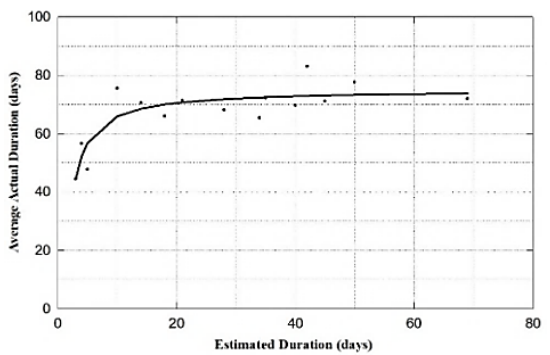

(f)

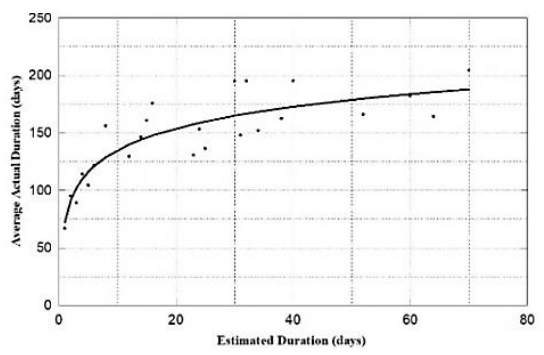

$(\mathrm{g})$

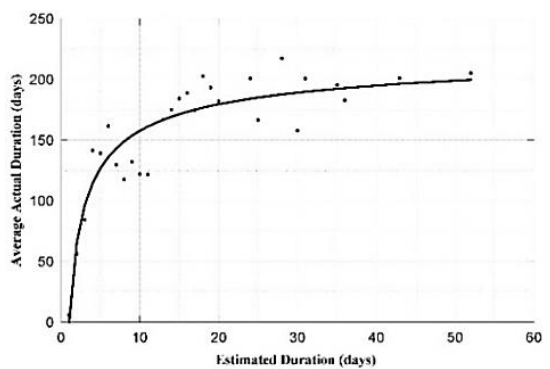

Fig. 5. Regression models for actual CAs duration in Kuwait analyzed by CSI divisions: a) division 02, b) division 03, c) division 04, d) division 08, (e) division $09, \mathrm{f}$ ) division 15 , and $\mathrm{g}$ ) division 16

The graphical analysis of CAs in Kuwait categorized according to CSI divisions is illustrated in Figure 5. It is worth noting that all regression models for CAs, particularly in Kuwait, follow nonlinear models except (08). In general, the majority of construction regression models in Kuwait start with exponential augmentation until an estimated duration of approximately 15 days. Thereafter, most trends continue with a considerable growth for all divisions except for (09) that follows a slight growth to become nearly stationary as in (5). In brief, the generated regression models for CAs demonstrate that (1) could be considered the best to represent the relationship between estimated durations and their respective actual durations.

\section{F. Regression Models for Construction Activities in an Individual Project Grouped by CSI Divisions}

Analysis was conducted on the construction activities of a distinctive large project in Kuwait. The project's budget was 55 million Kuwaiti Dinar and had scheduled nearly 6,400 CAs. The diagrammatic illustration of the regression models is shown in Figure 6 and the equations' constants are summarized in Table II. It is interesting to recognize that the exceedingly dominant equation that could be considered the best to describe numerous regression models of construction activities in an individual project is (3). On the other hand, a focus at Figures 5 and 6 reveals some striking dissimilarities in regression models for divisions (02), (03) and (15) in the selected project and between those of all studied projects in Kuwait as illustrated in Table II. Moreover, the regression model for division (03) is best represented by (6) for the case of construction activities an individual project:

$$
y=a+b \cdot x^{2}
$$

The provided information in Table II summarizes the cases of analysis, equations, equations' constants, and $\mathrm{r}^{2}$ coefficients for all regression models used. As an overall observation, the 
values of $r^{2}$ have evidenced considerable dissimilarities between engineering-procurement and construction regression models.

(a)

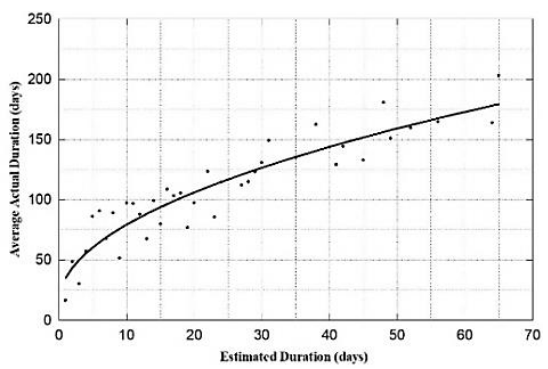

(b)

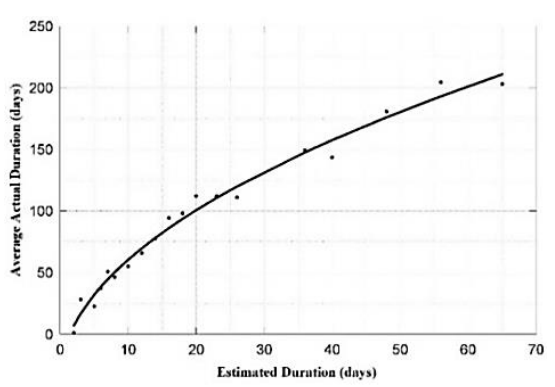

(c)

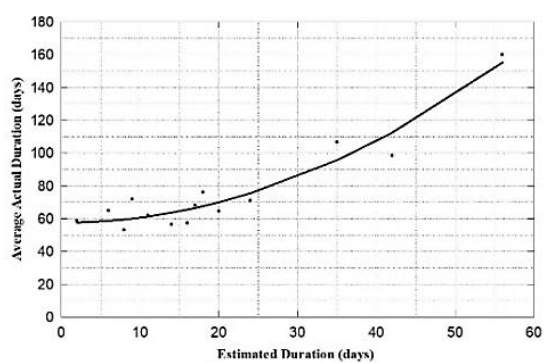

(d)

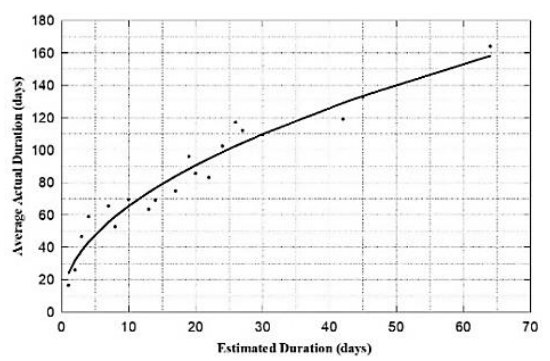

Fig. 6. Regression models for actual CA duration in a single project in Kuwait analyzed by CSI divisions: a) all divisions, b) division 02, c) division 03, and d) division 15

\section{G. Influence of Total Float on The Ratio of Actual Duration to Estimated Duration}

This study demonstrated that there is no direct relationship between the total float and the actual duration of activities as shown from the oscillation of results in Figure 7. Nevertheless, it could be presumed that preparing a schedule with a higher total float would lead to a higher time overrun. Correspondingly, it could be concluded that the duration ratio ( $\mathrm{Z}$-value) between the actual and estimated duration for various activities with total float range between 0 and 30 days does not follow a steady behavior. Whilst, the ratio seems more stable for activities with total float ranges between 30 and 200 days.
Another leading note is that the ratio is small for critical activities that have a zero-total float owing to the much more concern or concentration that was directed from the client or the contractor towards the critical or the semi-critical activities. Consequently, it is recommended to urge the project's stakeholders to focus commensurately towards all activities in order to avert delays.

TABLE II. REGRESSION MODELS, MODEL CONSTANTS, AND $\mathrm{r}^{2}$ FOR ALL CASES

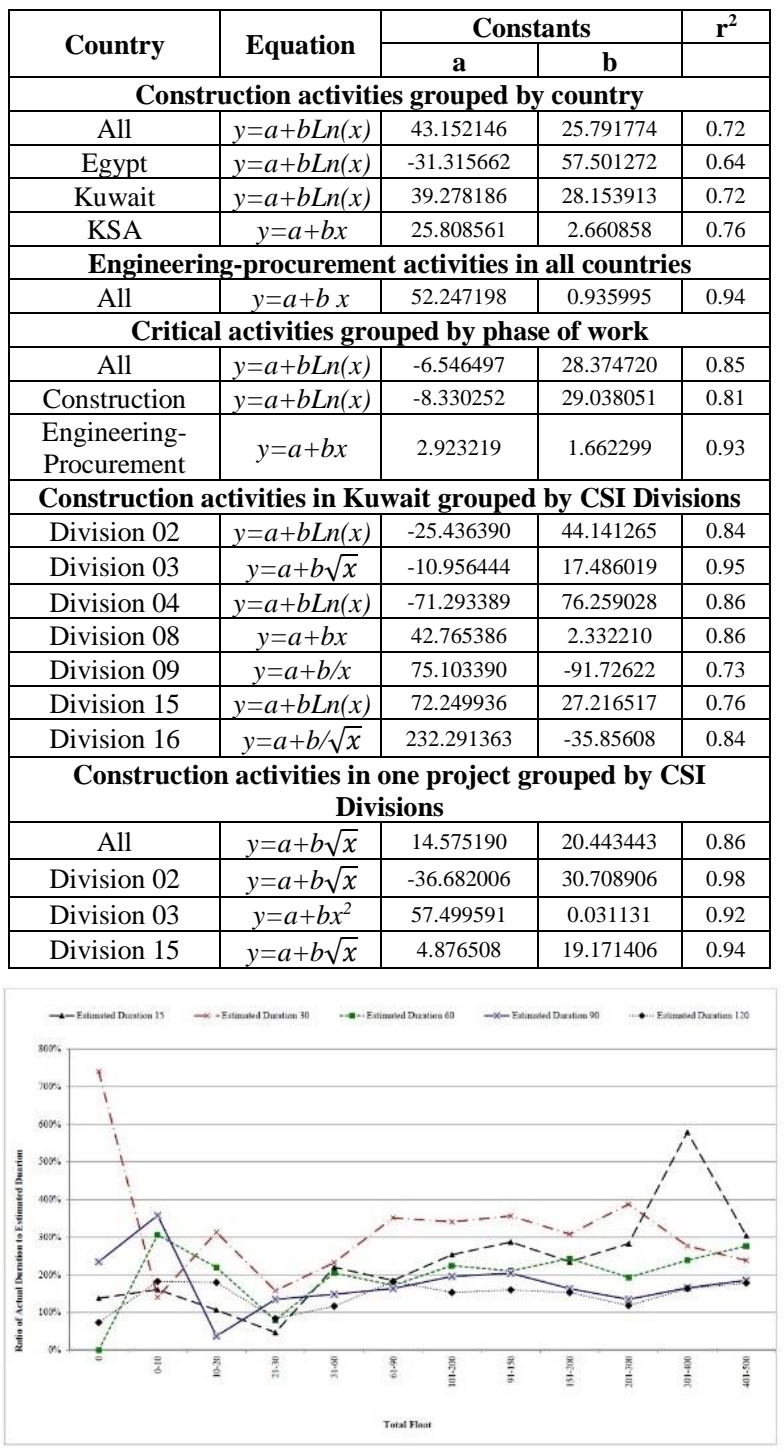

Fig. 7. Relationship between total float and increment in Z-value

\section{H. Relationship Between Activity Budget and Actual Duration}

Analysis was conducted to estimate activities' duration by evaluating the relationship between the estimated budget and the actual duration. The study was conducted on nearly 35,000 construction activities in Kuwait with a total budget of approximately 240 million Kuwaiti Dinar (1KD=3.5USD). The studied activities represent various projects and include most disciplines of work. It is found that the average budgeted rate per estimated duration is approximately $492.1 \mathrm{KD} /$ day, whereas 
the average budgeted rate per actual duration is around $83.7 \mathrm{KD} /$ day as summarized in Table III. In addition, it is found that the highest budget rate per actual duration is assigned to metal works, division (05), then to concrete works (03). The lowest allocated budget per day is for mechanical works (15) and electrical works (16).

TABLE III. BUDGET PER ED AND AD IN KUWAIT FOR CSI DIVISIONS

\begin{tabular}{|c|c|c|c|}
\hline \multirow{2}{*}{ CSI Division } & Division & Budget/ & Budget/ \\
& Budget & ED & AD \\
\cline { 3 - 4 } & \% & (KD/day) & (KD/day) \\
\hline 02 Site Works & 10.94 & 946.3 & 153.5 \\
\hline 03 Concrete Works & 40.91 & 694.5 & 203.5 \\
\hline 04 Masonry Works & 2.59 & 462.1 & 95.5 \\
\hline 05 Metal Works & 7.44 & $1,057.5$ & 234.7 \\
\hline 06 Wood and Plastic Works & 0.12 & 476.9 & 74.9 \\
\hline 07 Thermal and Moisture Protection & 2.89 & 293.8 & 73.7 \\
\hline 08 Doors and Windows Works & 3.08 & 383.3 & 70.3 \\
\hline 09 Finishes Works & 6.6 & 185.1 & 40.9 \\
\hline 14 Conveying System Works & 0.81 & 447.2 & 51.6 \\
\hline 15 Mechanical Works & 11.3 & 284.7 & 33.9 \\
\hline 16 Electrical Works & 11.65 & 504.7 & 45.3 \\
\hline All Divisions & & 492.1 & 83.7 \\
\hline
\end{tabular}

$\mathrm{ED}=$ estimated duration (days), $\mathrm{AD}=$ actual duration (days)

The regressing models that describe the relationship between the average actual duration and their assigned budget for all construction activities are best represented by (3). Moreover, the developed regression model is valid for construction activities with allocated budgeted values greater than $2,500 \mathrm{KD}$. The regression model starts with a rapid increase and thereafter the slope continues with a little lower growth as illustrated in Figure 8.

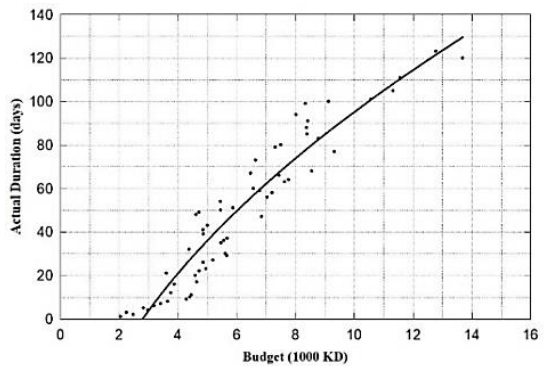

Fig. 8. Relationship between activity average budget (1000KD) and AD

\section{Relationship Between Activity Budget and AD for Each CSI Division}

An extra analysis was conducted to determine the relationship between the budget assigned to construction activities and their relevant actual durations. The objective of this study is to derive estimated durations for activities of construction projects with higher degrees of reliability by utilizing the activity's budgeted value. It is found that the cases of all divisions together and division (15) follow the same regression model that is represented by (3) whereas, divisions (03), (09), and (16) follow regression models represented by (1) and division (02) follows (2). As shown in Figure 9, the trends for divisions classified as civil works such as divisions (02), (03) and (04) start with quite moderate increasing rates. Meanwhile, the curves for divisions (15) and (16) that represent electro-mechanical works start with a dramatic increase. This increase can be attributed to the distribution of items' budget over their relevant construction activities. Whereas, the electromechanical first fix activities always have smaller budgets than second or third fix activities.

(a)
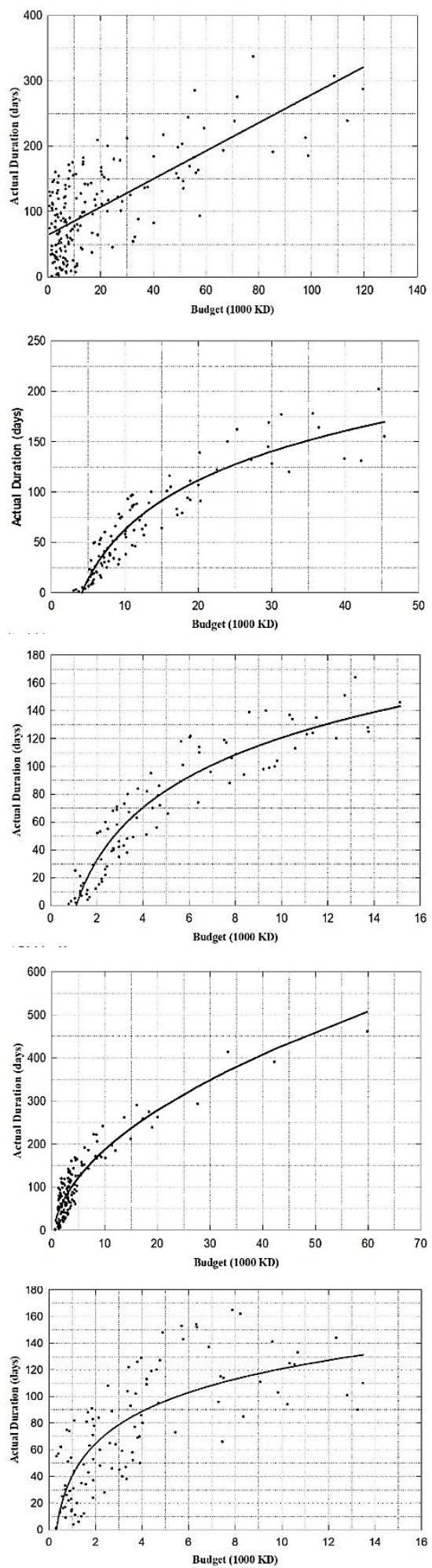

Fig. 9. Regression models for predicting the relationship between CA budget and $\mathrm{AD}$ in Kuwait: a) division 02, b) division 03, c) division 09, d) division 15, e) division 16 
TABLE IV. REGRESSION MODELS, MODEL CONSTANTS, AND $\mathrm{r}^{2}$ FOR CONSTRUCTION ACTIVITY BUDGET PER ADS FOR EACH CSI DIVISION

\begin{tabular}{|c|c|c|c|c|}
\hline \multirow{2}{*}{ Division } & \multirow{2}{*}{ Equation } & \multicolumn{2}{|c|}{ Constants } & $\mathbf{r}^{2}$. \\
\cline { 3 - 5 } & & $\mathbf{a}$ & $\mathbf{b}$ & \\
\hline All Divisions & $y=a+b \cdot \sqrt{x}$ & -106.850042 & 63.9112922 & 0.90 \\
\hline Division (02) & $y=a+b . x$ & 63.92006073 & 2.14839692 & 0.52 \\
\hline Division (03) & $y=a+b \operatorname{Ln}(x)$ & -100.7569902 & 70.9025097 & 0.87 \\
\hline Division (09) & $y=a+b \operatorname{Ln}(x)$ & -5.451089338 & 54.7762879 & 0.88 \\
\hline Division (15) & $y=a+b \sqrt{x}$ & -35.28792636 & 70.0599205 & 0.85 \\
\hline Division (16) & $y=a+b \operatorname{Ln}(x)$ & 40.44178744 & 34.9312426 & 0.57 \\
\hline
\end{tabular}

Furthermore, the first fix activities often have interdependencies with various disciplines that always cause time slippage and duration overrun. Meanwhile, the third fix activities are always installed in a short time and during one session. Therefore, contractors should plan and make the necessary coordination for electromechanical first fix activities at earlier stages. In stark contrast, however, the same equipment from different vendors or brands may increase the assigned budget, but will not have a tangible impact on installation time.

\section{SUMMARY AND CONCLUSIONS}

Comprehensive statistical regression models were developed using real data from 13 large construction projects in Egypt, Kuwait and KSA including approximately 84,000 EPC activities representing most disciplines of work. The regression models delineate the relationship between activities estimated and actual durations to predict actual durations based on their pertinent estimated duration through conventional estimation techniques. In addition, regression models were established utilizing 35,000 construction activities to predict the activities' duration based on their budgets. It was found that:

- The shorter the estimated duration is, the higher the duration slippage will be. Therefore, contractors are recommended to prepare work breakdown structure with activities with no less duration than 15 days. Most regression models for construction activities in Kuwait start with rapid increasing slope until an estimated duration of about 15 days.

- A project's overall duration based on our proposed regression models may be greater than that conventionally calculated. Nevertheless, the proposed values allow the opportunity for early planning through implementing innovative methodologies and substitutional plans.

- Average actual duration values relevant to estimated durations less than 30 days are very high, and the highest values for this range were recorded in Kuwait.

- The Z-value ratio for construction activities with duration less than 40 days is higher than engineering-procurement activities. The ratio becomes higher for engineeringprocurement activities with duration greater than 100 days.

- There is no proof for a direct relationship between total float and the actual duration slippage of activities. The Zvalue ratio is small for critical activities which have zerototal float.
- The overall budget rates of all activities per estimated duration and per actual duration are about 492.1 and 83.7 $\mathrm{KD} /$ day respectively.

- The highest budget rate per actual duration is assigned to division (05), metal works, and then to division (03), concrete works. The lowest budget rates per actual duration are divisions (15) and (16), mechanical and electrical works.

- The regression models for electro-mechanical works start with an exponential increase because the first fix activities always have smaller budgets than the second or third fix activities. Meanwhile, the first fix activities often have time slippage and duration overrun. Therefore, contractors should plan and coordinate more accurately for electromechanical first fix activities at early stages.

\section{REFERENCES}

[1] A. Enshassi, J. Abu-Mosa, "Risk Management in Building Projects: Owners' Perspective", The Islamic University Journal (Series of Natural Studies and Engineering), Vol. 16, No. 1, pp. 95-123, 2008

[2] F. Moavenzadeh, J. A. K. Rossow, The Construction Industry in Developing Countries, Massachusetts Institute of Technology, Technology Adaptation Program, 1975

[3] W. Menesi, Construction Delay Analysis under Multiple Baseline Updates, MSc Thesis, University of Waterloo, 2007

[4] K. C. Lyer, K. N. Jha, "Critical Factors Affecting Schedule Performance: Evidence from Indian construction Projects", Journal of Construction Engineering and Management, Vol. 132, No. 8, pp. 871881,2006

[5] I. A. Majid, Causes and Effects of Delays in Aceh Construction Industry, MSc Thesis, University Technology Malaysia, 2006

[6] S. A. Assaf, M. Al-Khalil, M. Al-Hazmi, "Causes of Delay in Large Building Construction Projects", Journal of Management in Engineering, Vol. 11, No. 2, pp. 45-50, 1995

[7] M. A. Al-Ghafly, Delay in the Construction of Public Utility Projects in Saudi Arabia, MSc Thesis, King Fahd University of Petroleum \& Minerals, 1995

[8] I. I. Falqi, Delays in Project Completion: a Comparative Study of Construction Delay Factors in Saudi Arabia and the United Kingdom, MSc Thesis, Heriot-Watt University, 2004

[9] S. A. Assaf, S. Al-Hejji, "Causes of Delay in Large Construction Projects", International Journal of Project Management, Vol. 24, No. 4, pp. $349-357,2006$

[10] P. A. Koushki, K. Al-Rashid, N. Kartam, "Delays and Cost Increases in the Construction of Private Residential Projects in Kuwait", Journal of Construction Management and Economics, Vol. 23, pp. 285-294, 2005

[11] H. M. Al-Tabtabai, "Causes for Delays in Construction Projects in Kuwait", Engineering Journal of the University of Qatar, Vol. 15, pp. $19-37,2002$

[12] S. M. El-Sayegh, "Risk Assessment and Allocation in the UAE Construction Industry", International Journal of Project Management, Vol. 26, No. 4, pp. 431-438, 2008

[13] A. H. Al-Momani, "Construction Delay: a Quantitative Analysis", International Journal of Project Management, Vol. 18, No. 1, pp. 51-59, 2000

[14] W. M. Chan, M. M. Kumaraswamy, "Compressing Construction Durations: Lessons Learned from Hong Kong Building Projects", International Journal of Project Management, Vol. 20, No. 1, pp. 23-35, 2002

[15] K. Strong, A. Kandil, T. H. Maze, Flexible Start / Fixed Duration Contracting for Construction of Transportation Projects: a Case Study of the Paseo Bridge Maintenance Project, Center for Transportation Research and Education, Iowa State University, 2007 
[16] D. R. Ogunsemi, G. O. Jagboro, "Time-Cost Model for Building Projects in Nigeria", Construction Management and Economics, Vol. 24, No. 3, pp. 253-258, 2006

[17] S. A. Bustani, Y. D. Izam, "Predictive Duration Models for Building Construction Projects in Nigeria", Journal of Environmental Sciences, Vol. 3, No. 2, pp. 131-135, 1999

[18] J. Martin, T. K. Burrows, I. Pegg, "Predicting Construction Duration of Building Projects", XXIII International FIG Congress, Munich, Germany, October 8-13, 2006

[19] E. Odabasi, Models for Estimating Construction Duration: an Application for Selected Buildings on the METU Campus, MSc Thesis, Middle East Technical University, 2009

[20] S. T. Ng, M. Mak, R. M. Skitmore, M. Varnam, "The Predictive Ability of Bromilow's Time-Cost Model", Construction Management and Economics, Vol. 19, No. 2, pp. 165-173, 2001

[21] I. A. Choudhury, "Study of the Factors of Construction Time for Educational Projects in Texas", American Society for Engineering Education (ASEE), San Antonio, Texas, USA, June 10-13, 2012

[22] Z. A. Chehade, Towards the Determination of the Construction Contract Duration for Building Projects Prior to the Bidding Stage, MSc Thesis, American University of Beirut, 2005

[23] A. A. Abu-Hammad, S. M. Alhaj-Ali, G. J. Sweis, A. Bashir, "Prediction Model for Construction Cost and Duration in Jordan", Jordan Journal of Civil Engineering, Vol. 2, No. 3, pp. 250-266, 2008

[24] A. A. Abu-Hammad, S. M. Alhaj-Ali, G. J. Sweis, R. J. Sweis, "Statistical analysis on the Cost and Duration of Public Building Projects", Journal of Management in Engineering, Vol. 26, No. 2, pp. 105-112, 2010

[25] A. Prateapusanond, A Comprehensive Practice of Total Float PreAllocation and Management for the Application of a CPM-Based Construction Contract, PhD Thesis, Virginia Polytechnic Institute and State University, 2003

[26] E. M. Willis, Scheduling Construction Projects, John Wiley \& Sons, 1986

[27] M. T. Callahan, D. G. Quackenbush, J. Rowings, Construction Project Scheduling, McGraw-Hill, 1992

[28] D. J. Harmelink, M. A. Bernal, "Simulating Haul Durations for Linear Scheduling", 1998 Winter Simulation Conference, Washington DC, USA, December 13-16, 1998

[29] C. Hendrickson, D. Martinelli, D. Rehak, "Hierarchical Rule-Based Activity Duration Estimation", Journal of Construction Engineering, Vol. 113, No. 2, pp. 288-301, 1987

[30] T. M. Cheng, H. T. Wu, "Simulation with Fuzzy Durations", International Journal of Applied Science and Engineering, Vol. 4, No. 2, pp. 189-203, 2006

[31] PMI, A Guide to the Project Management Body of Knowledge (PMBOK@ Guide), Project Management Institute, 2017

[32] S. Biruk, P. Jaskowski, "On the Problems of Modelling and Reliability Assessment of Construction Projects Duration”, Journal of International Group on Reliability, Vol. 4, No. 19, pp. 6-14, 2010

[33] A. A. Csebfalvi, "Unified Model for Resource-Constrained Project Scheduling Problem with Uncertain Activity Durations", International Journal of Optimization in Civil Engineering, Vol. 2, No. 3, pp. 341-355, 2012

[34] H. Zhang, C. M. Tam, H. Li, "Modelling Uncertain Activity Duration by Fuzzy Number and Discrete-Event Simulation", European Journal of Operational Research, Vol. 164, No. 3, pp. 715-729, 2005

[35] W. M. Youssef, K. M. El-Dash, O. M. Ramadan, "Construction Activities Duration Patterns in the Middle East", International Journal of Construction Engineering and Management, Vol. 2, No. 4, pp. 122-135, 2013

[36] W. M. Youssef, Probabilistic Models for Construction Projects' Durations in The Middle East, PhD Thesis, Cairo University, 2014

[37] I. Abdul-Rashid, B. Bakarman, "Risk Assessment and Analysis for Construction Contractors in Egypt", 11th International Colloquium on Structural and Geotechnical Engineering, Cairo, Egypt, May 17-19, 2005
[38] M. I. Al-Khalil, M. A. Al-Ghafly, "Important Causes of Delay in Public Utility Projects", Journal of Construction Engineering and Management, Vol. 17, No. 5, pp. 647-655, 1999 